\title{
El Partido Socialista y el movimiento sindical tras la conquista de la Confederación General del Trabajo (1935- 1937)
}

\author{
The Socialist Party and the trade union movement after the \\ conquest of the General Confederation of Labor (1935-1937)
}

\author{
Diego Ceruso \\ Universidad de Buenos Aires, \\ Consejo Nacional de Investigaciones Científicas y Técnicas, Argentina \\ diegoceruso@gmail.com
}

\begin{abstract}
Resumen
Desde sus orígenes, aunque con fuertes debates, la voluntad oficial, justista digamos, del Partido Socialista (PS) fue la de escindir el plano político del gremial. Esta autonomía, materializada en la 'Declaración de Avellaneda' del XIV Congreso Ordinario en 1918, formaba parte de una concepción más amplia sobre la necesidad de construir una opción partidaria reformista, que buscara la integración al sistema social y político y que subordinara la conflictividad entre capital y trabajo a otros elementos más globales, entre otras características. Este trabajo se propone revisar el proceder del PS en el movimiento sindical a partir del 'golpe interno' ocurrido en la Confederación General del Trabajo (CGT), a fines de 1935, momento en cual los socialistas se hacen cargo de la conducción de dicha central obrera, hasta la elección de José Domenech como secretario general, en junio de 1937. La hipótesis que guía nuestra investigación es que durante este periodo, la mencionada modulación de la política oficial ocurrida entre 1930 y 1935 fue desmantelada permitiendo al PS retomar la senda de la escisión del plano político del gremial expresada en 1918 y presente, de hecho, con anterioridad.

En este recorrido analizaremos la opinión de los cuadros gremiales, los partidarios y el rol de la Comisión Socialista de Información Gremial (CSIG). Ello lo haremos mediante el análisis de fuentes internas del PS, su periódico La Vanguardia, y otras publicaciones de relevancia como Anuario Socialista, Revista Socialista, entre otros.
\end{abstract}

\section{Palabras Clave}

Partido Socialista; sindicalismo; Argentina; década de 1930; Confederación General del Trabajo 


\title{
El Partido Socialista y el movimiento sindical tras la conquista de la Confederación General del Trabajo (1935-1937)
}

\begin{abstract}
From its beginnings, although with strong debates, the official will of the Socialist Party (PS) was to split the political level of the union. This autonomy, embodied in the Avellaneda Declaration of the XIV Ordinary Congress in 1918, was part of a broader conception of the need to build a reformist party option that sought integration into the social and political system and subordinate the conflict between Capital and labor to other more global elements, among other characteristics. This paper aims to review the behavior of the PS in the trade union movement after the 'internal coup' in the General Confederation of Labor (CGT), at the end of 1935, at which point the Socialists take over the management of the central Until the election of José Domenech as general secretary in June 1937. The hypothesis that guides our investigation is that during this period, the aforementioned modulation of the official policy between 1930 and 1935 was dismantled allowing the PS to resume the path of the split of the political plane of the union expressed in 1918 and present, in fact, before.

In this course we will analyze the opinion of the trade union cadres, the supporters and the role of the Socialist Commission for Trade Information (CSIG). This will be done through the analysis of internal sources of the PS, its newspaper La Vanguardia, and other relevant publications such as Anuario Socialista, Revista Socialista, among others.
\end{abstract}

\section{Keywords}

Socialist Party; syndicalism; Argentina; 1930s; General Confederation of Labor

Durante el periodo analizado, el movimiento obrero y las izquierdas ocuparon un importante rol en la vida política, económica, social y cultural del país. De este modo, el estudio aquí encarado supone un aporte a la historia argentina en el que nuestra intención es atender al vínculo entre ambos sujetos en cuestión. La óptica relacional entre el movimiento obrero y las izquierdas entendemos que enriquece el análisis y permite observar el proceso de constitución mutua sin por ello desatender a sus aspectos específicos. En este caso, nuestra apuesta recae en la indagación del Partido Socialista (PS) en su lazo con el movimiento sindical en la década de 1930 con la intención que ello nos permita un mejor conocimiento de la propuesta y el nivel de concreción de la articulación entre lo sindical y lo político de una de las empresas políticas de izquierda de más larga tradición e importancia del país. El repaso por la experiencia del PS en el universo sindical conserva aún múltiples interrogantes y examinar el vínculo entre ambos sujetos ilumina al mismo tiempo una parte importante de la historia del socialismo, y de la izquierda en general, y del movimiento obrero argentino de la primera mitad del siglo XX.

En particular, esa experiencia del PS en la década de 1930 ofrece aún esferas desde donde abordarla dado que no ha sido una temática recurrente en los estudios académicos. El trabajo de María Cristina Tortti se erige como una referencia ineludible pues abordó la práctica gremial del PS en los años treinta, las fricciones motivadas por la tendencia a la disociación de la herramienta política y el proceder 


\section{Diego Ceruso}

sindical y los enfrentamientos y rupturas que de esto último se derivaron. ${ }^{1}$ Hiroshi Matsushita también encaró la investigación del desempeño socialista en estos años aunque el enfoque estuvo en la Confederación General del Trabajo (CGT) y las relaciones que de allí se desprendían con el Estado y el resto de las corrientes políticas, el sindicalismo primero y el comunismo después. ${ }^{2}$ Asimismo, en un trabajo anterior procuramos revisar detenidamente el debate interno en el PS acerca del vínculo partidario con el gremialismo entre 1930 y $1935 .{ }^{3}$ Allí pudimos observar un período en el cual la política consagrada en la 'Declaración de Avellaneda' del XIV Congreso Ordinario en julio de 1918 fue puesta en cuestión. Desde sus orígenes, aunque con fuertes debates, la voluntad oficial, emanada de la visión de Juan B. Justo, fue la de escindir el plano político del gremial. ${ }^{4}$ Esta autonomía de ámbitos, materializada en la mencionada 'Declaración', era una expresión de una concepción más amplia sobre la necesidad de construir una opción partidaria reformista, como se ha señalado: "el problema en el socialismo argentino era más profundo que una mera desarticulación entre lo sindical y lo político. Lo que existía era una concepción que subordinaba las contiendas entre el trabajo y el capital a una faena de reforma e integración social, idealizando la lucha de clases como una suerte de disputa retórica de proyectos en el terreno neutro de un ágora. El PS desconfiaba de las prácticas de autodeterminación de las masas y de las capacidades creadoras de la lucha de clases, la que debía canalizarse para evitar sus desbordes y el despliegue de su potencialidad barbárica". ${ }^{5}$ Pero esta desarticulación de esferas, que si se quiere ir más allá fue incluso una disociación con algunos aspectos centrales de la lucha y la organización obrera, estuvo sujeta a fuertes tensiones internas y cuestionamientos que buscamos evidenciar en la coyuntura de la primera mitad de la década de 1930. Durante esos años, el sector compuesto principalmente por cuadros gremiales y liderados por Francisco Pérez Leirós pareció tener una política más activa y mayor presencia en las publicaciones partidarias. A partir de 1930, pero con marcado énfasis desde 1932, aquellos que propiciaban una relación más directa y fluida entre el Partido y los sindicatos fueron ganando peso en la Comisión Socialista de Información Gremial (CSIG), representación en los Congresos y

\footnotetext{
${ }^{1}$ María Cristina Tortti. "Estrategia del Partido Socialista. Reformismo político y reformismo sindical”. Conflictos y Procesos de la Historia Argentina Contemporánea, № 34, Buenos Aires, CEAL, 1989.

2 Hiroshi Matsushita. Movimiento Obrero Argentino, 1930-1945: Sus proyecciones en los orígenes del peronismo. Buenos Aires, Hyspamérica, 1986.

${ }^{3}$ Diego Ceruso. "El Partido Socialista y la cuestión gremial. Debates internos durante la primera mitad de la década infame". Archivos de historia del movimiento obrero y la izquierda, V, 10, Buenos Aires, 2017, pp. 119-139.

${ }^{4}$ Ricardo Martínez Mazzola. "La neutralidad como problema y como solución. La política gremial del Partido Socialista después de la ruptura sindicalista". Identidades, I, 1, Buenos Aires, 2017, pp. 1-20. "El Partido Socialista no debe inmiscuirse en la organización gremial. Colectivamente sólo puede servirla desde afuera, en cuanto a las leyes, el gobierno y la administración pública atañen a la organización gremial". Juan B. Justo. "La organización obrera y el Partido Socialista". Obras de Juan B. Justo, tomo 6, La realización del socialismo. Buenos Aires, La Vanguardia, 1947.

${ }^{5}$ Hernán Camarero. "Del auge al declive: las corrientes de izquierda y los trabajadores antes del peronismo. Elementos para una interpretación teórica e historiográfica global". Iberoamérica Global, núm. 2, Jerusalém, 2011, pp. 49-79.
} 


\section{El Partido Socialista y el movimiento sindical tras la conquista de la Confederación General del Trabajo (1935-1937)}

visibilidad en los medios del PS. Prueba de ello son las composiciones de la Comisión Gremial en donde la mayoría de sus integrantes se enrolaban en las posiciones encabezadas por el líder de los municipales, la presencia regular de intervenciones críticas a la dirección del PS en relación al desempeño sindical en la prensa y otros órganos de difusión editorial y, quizá el punto más sintomático, el Despacho Gremial del Congreso de Santa Fe en 1934 que contrariaba la postura tradicional de la 'Declaración de Avellaneda'.

A nuestro entender, esto no implicó un cambio de estrategia del PS sino más bien una modulación de la política oficial. Había, al menos, dos fuertes motivaciones que influyeron en esta modificación táctica. La primera, la presencia de los sindicalistas en la conducción de la CGT que llevaron al extremo su perfil negociador, pragmático, moderado y conciliador junto a su discurso neutralista, de rechazo a las influencias políticas. Esto permitió polarizar al PS y contraponer a ello una política más activa en el movimiento sindical que se expresó no solo en la lucha contra el fascismo sino además en las críticas al cuerpo de ideas tradicional del sindicalismo. ${ }^{6}$ La segunda de las causas pareció ser de índole interna. La existencia de una relanzada 'izquierda' partidaria que fustigaba a la dirección y planteaba una serie de alteraciones programáticas, estratégicas y estructurales que redefinirían el rumbo, más bien el sentido, del PS.7 Proponíamos que no resulta inverosímil que la conducción partidaria haya propiciado una mayor presencia del grupo encabezado por Pérez Leirós para mostrarse permeable a las críticas referidas al rol en el ámbito gremial y así atemperar, parcialmente, la influencia del sector de Benito Marianetti en la base del PS. Un tercer factor que pudo influir en esta variación política pudo ser la intención de la dirección del Partido de atender la creciente incidencia comunista entre los trabajadores industriales principalmente. ${ }^{8}$

Pero este escenario se desvaneció durante 1935 por dos motivos fundamentales: el primero, el sector 'izquierdista' fue paulatinamente diezmado entre el cónclave de Santa Fe y el Congreso Extraordinario para la reforma de estatutos de 1935; el segundo, el núcleo dirigente sindicalista fue depuesto de la CGT en diciembre de ese mismo año. De este modo, según lo que señalábamos, las causas

\footnotetext{
${ }^{6}$ Un reciente trabajo analiza el proceder sindicalista en la conducción de la CGT entre 1930 y 1935. Leandro García. "En torno al concepto de "prescindencia": la corriente sindicalista al frente de la CGT (1930-1935)". Archivos de historia del movimiento obrero y la izquierda, V, 10, Buenos Aires, 2017, pp. 95-115.

${ }^{7}$ Nicolás Iñigo Carrera. "Alternativas revolucionarias en los '30: la Alianza Obrera Spartacus y el Partido Socialista Obrero". En Hugo Biagini, y Arturo Roig (directores), El pensamiento alternativo en la Argentina del siglo XX. Tomo II. Obrerismo, vanguardia, justicia social (1930-1960), Buenos Aires, Editorial Biblos, 2006; Carlos Miguel Herrera. "Corrientes de izquierda en el socialismo argentino, 1932-1955". Nuevo Topo. Revista de historia y pensamiento crítico, 2, Buenos Aires, 2006, pp. 127 153. Ilana Martínez. Por la vuelta a Marx. El ala izquierda del Partido Socialista Argentino, 1929-1935. Tesis de maestría, Buenos Aires, Universidad Nacional de General San Martín 2012.

${ }^{8}$ Hernán Camarero. Comunismo y movimiento obrero en la Argentina, 1914-1943. Tesis de doctorado, Buenos Aires, Universidad de Buenos Aires, 2008. Diego Ceruso. La izquierda en la fábrica. La militancia obrera industrial en el lugar de trabajo, 1916-1943. Colección Archivos, Buenos Aires, Imago Mundi, 2015.
} 


\section{Diego Ceruso}

principales que habrían motivado aquella modulación en la estrategia sindical ya no se encontraban presentes ni representaban un desafío al PS. El interrogante, y objetivo principal de este trabajo, es examinar si con posterioridad a 1935, y ya en la conducción de la CGT, hasta la toma de posesión de la secretaría general por parte de José Domenech en junio de 1937, ese panorama se modificó. ¿Eso permitió a la dirección del PS retomar la senda de la escisión del plano político del gremial expresada en 1918 y presente, de hecho, prácticamente desde sus orígenes? ¿Las voces disonantes de la estrategia oficial quedaron relegadas y la política enarbolada por los socialistas en la CGT replicó una tendencial pero cada vez más marcada autonomía de las corrientes políticas? ¿Cuál fue el rol de la CSIG, elemento más dinámico de aquellas críticas y bastión de quienes profesaban una modificación en la vinculación entre el Partido y los sindicatos entre 1930 y 1935, durante la segunda mitad de los años treinta? Estas preguntas constituyen el hilo conductor del trabajo y orientan la investigación en todo su recorrido.

Además, existen elementos que deben ser señalados para una mejor contextualización del periodo que abordamos y que atañen a los sujetos que aquí analizamos. En primer lugar, un aspecto estructural fue la consolidación del crecimiento económico iniciado unos años antes que repercutió en un descenso de la desocupación. ${ }^{9}$ En paralelo, el estancamiento de los salarios reales, la exigua legislación laboral, las extensas jornadas de trabajo y las malas condiciones en los sitios de producción estructuraban un contexto de insatisfacción para la clase obrera. La coyuntura de crecimiento y demandas obreras insatisfechas construyó una situación en la cual los conflictos obreros, y el aumento de la influencia sindical en los mismos, proliferaron. En segundo término, luego de intentar con sucesivos levantamientos armados, la Unión Cívica Radical declinó dicha opción y levantó su estrategia de abstencionismo posicionándose como la principal alternativa electoral a la Concordancia, relegando las aspiraciones de los socialistas y los demoprogresistas. ${ }^{10}$ En tercer lugar, y en el campo de las izquierdas, dos novedades agitaron el escenario. El Partido Comunista (PC) abandonó durante 1935 la estrategia de 'clase contra clase' y abrazó la del 'frente popular' que habilitó acuerdos con las fuerzas obreras 'reformistas', e incluso con los sectores 'progresistas' de la burguesía, que posibilitaron la construcción de alianzas bajo preceptos antiimperialistas y antifascistas. ${ }^{11} \mathrm{El}$ impacto de este abrupto y polémico viraje no demoró en percibirse entre los trabajadores. Conviene señalar tres consecuencias inmediatas: se inició el proceso de disolución del Comité de Unidad Sindical Clasista, se planteó la posibilidad de incorporarse a la CGT y se comenzó a discutir acuerdos con las otras corrientes con la intención de desandar el camino de los sindicatos 'rojos', en la práctica exclusivamente comunistas, y aunar fuerzas en

\footnotetext{
${ }^{9}$ Adolfo Dorfman. Historia de la industria argentina. Buenos Aires, Hyspamérica, 1986.

${ }^{10}$ Un estudio reciente y pormenorizado de este y otros aspectos del primer quinquenio de la década del treinta en: Nicolás Iñigo Carrera. La otra estrategia. La voluntad revolucionaria (1930-1935). Buenos Aires, PIMSA-Imago Mundi, 2016.

${ }^{11}$ Hernán Camarero. A la conquista de la clase obrera. Los comunistas y el mundo del trabajo en la Argentina, 1920-1935. Buenos Aires, Siglo XXI, 2007.
} 


\section{El Partido Socialista y el movimiento sindical tras la conquista de la Confederación General del Trabajo (1935-1937)}

estructuras gremiales conjuntas. Otro de los elementos a destacar estuvo relacionado con los anarquistas. El Comité Regional de Relaciones Anarquistas había sido creado en 1932 y, en la práctica, se desempeñaba como una organización específica de un revitalizado, aunque limitado en sus fuerzas concretas, anarquismo en el país. Pero durante 1935 se produjo el salto definitivo hacia la estructura de la Federación Anarco Comunista Argentina. Advertían que el anarquismo debía responder a la nueva coyuntura económica y política con nuevas prácticas. ${ }^{12}$ Por último, otro mojón por repasar es el aumento en la lucha obrera. Durante 1935, se sucedieron una serie de importantes conflictos entre los que conviene destacar la huelga de los obreros madereros entre mayo y julio, la huelga de la construcción de octubre y que se prolongó por varios meses y la huelga general de enero de $1936 .{ }^{13}$ De conjunto, los aspectos marcados coadyuvaban a delinear un escenario de impulso a la lucha de los trabajadores y a una mayor presencia de las izquierdas en la organización sindical en los años iniciales de la segunda mitad de los años treinta.

\section{El cambio de coyuntura en la CGT}

En la primera mitad de la década del treinta la convivencia de los socialistas y los sindicalistas en la CGT distaba de ser cordial. Las desavenencias entre ambos sectores se encontraban a la orden del día. El primer grupo integrado por miembros de la CSIG, socialistas propensos a buscar mayor presencia orgánica del partido en los gremios y sindicalistas descontentos con la conducción reclamaban una mayor representación de los sindicatos a los que pertenecían (principalmente ferroviarios pero también tranviarios, comercio y municipales) en los cargos directivos aunque no se privaron de anclar su crítica en la prescindencia política que declamaba la central. ${ }^{14}$ El otro sector estaba formado mayoritariamente por los sindicalistas que controlaban la CGT. En diciembre de 1935 el clima de enfrentamiento se exacerbó cuando la Unión Ferroviaria (UF), bajo la secretaría general del socialista José Domenech, pretendió modificar sus delegados en la central en el marco del llamado de la dirigencia cegetista al largamente demorado Congreso Constituyente para marzo de 1936. El 12 de diciembre los eventos se precipitaron cuando los opositores ingresaron por la fuerza a la sede de la CGT y declararon depuestas a las autoridades. ${ }^{15}$

\footnotetext{
12 Resoluciones adoptadas en el Congreso Constituyente de la Federación Anarco Comunista Argentina, Dirección de Inteligencia de la Policía de la Provincia de Buenos Aires (DIPBA), pp. 13-14.

13 Nicolás Iñigo Carrera. La estrategia de la clase obrera, 1936 (2000). Buenos Aires, Ediciones Madres de Plaza de Mayo, 2004.

14 Julio Godio. El movimiento obrero argentino (1930-1943). Socialismo, comunismo y nacionalismo obrero. Buenos Aires, Legasa, 1989, pp. 125 y ss.

15 Las dos versiones en Jacinto Oddone. Gremialismo proletario argentino. Buenos Aires, La Vanguardia, 1949, pp. 332-351 y Sebastián Marotta. El movimiento sindical argentino. Su génesis y desarrollo. Tomo III. Período 1920-1935. Buenos Aires, Lacio, 1970, pp. 411-433. Además en: “Ayer hizo crisis el conflicto latente en la central obrera", La Vanguardia, 10320, 13/12/1935, p. 7; “Cómo se premeditó y cómo se consumó el asalto a la CGT", Libertad, diario de la mañana, ("Órgano oficial del Partido Socialista Independiente"), IX, 2608, 29/12/1935, p. 1.
} 


\section{Diego Ceruso}

El golpe interno provocó la división y, a partir de allí, existieron dos CGT: la 'socialista', con mayor número de sindicatos y obreros afiliados y cuyo núcleo eran los gremios ferroviarios (UF y La Fraternidad) junto con los tranviarios, comercio y municipales; y la 'sindicalista', compuesta por un escaso número de empleados telefónicos y marítimos, principalmente. La primera central fue reconocida como CGT Independencia, mientras que la sindicalista como CGT Catamarca; en ambos casos el nombre se debió a las calles en donde se ubicaban sus oficinas. Con la toma de las riendas de los socialistas en la CGT Independencia, los comunistas vieron la posibilidad de sumarse a la central obrera, en línea con la orientación de 'frente popular'.

Tras los hechos de diciembre, la Federación Gráfica Bonaerense (FGB), de larga tradición socialista y coyunturalmente por aquellos años con presencia relevante de la 'izquierda' del PS en sus cuadros dirigentes, y a quien en octubre de 1935 la dirigencia sindicalista le había negado el reingreso a la CGT, efectuaba su propio balance de lo sucedido y caracterizaba a la dirección depuesta: "con el taparrabos de una pretendida 'prescindencia' que nunca fue un obstáculo para que se prendieran de los faldones de los políticos de la burguesía (...)".16 Y, aunque sin negar la participación de socialistas en el golpe de diciembre de 1935, la CSIG desmentía su acción coordinada: "que la Comisión Socialista de Información Gremial no ha tenido ninguna participación en los acontecimientos que provocaron la cesantía del Comité Sindical Nacional, aunque considera este hecho saludable para el proletariado argentino". ${ }^{17}$ Más allá de la coordinación, la presencia socialista y de integrantes de la CGIG en los eventos de diciembre resultaba inocultable. De los 27 integrantes del grupo que tomó la CGT, cuatro eran miembros de la CSIG. ${ }^{18} \mathrm{~A}$ mediados de 1935, y ya con el nuevo estatuto que dejaba de lado la elección en asamblea de afiliados, el CE del PS había designado a los integrantes de la CSIG, cuyo secretario general era Roberto Testa. ${ }^{19}$

En 1936 la CGT Independencia realizó su Congreso Constituyente y los comunistas se incorporaron a la central. De este modo, la tradicional presencia socialista y de los sindicalistas afines junto a la creciente inserción comunista en la industria afincada en su pericia organizativa, sentaron las bases de una pujante estructura. ${ }^{20}$ Con este ingreso y el de algunos gremios autónomos, la CGT aglutinaba para mediados de 1936 al 70\% de los obreros sindicalizados. El mapa sindical

16 "El proletariado se emancipó de la camarilla que mangoneaba la Confederación General del Trabajo", El Obrero Gráfico, órgano de la Federación Gráfica Bonaerense, XXIX, 254, diciembre de 1935 y enero de 1936, p. 8.

${ }^{17}$ Acción Gremial, editado por la Comisión Socialista de Información Gremial, 41, enero de 1936. Nota transcripta en XXIII Congreso Ordinario (XXX Congreso Nacional), Talleres Gráficos La Vanguardia, 1936, p. 53.

${ }^{18}$ Los miembros de la CSIG presentes en la asonada eran Pérez Leirós, Juan Brennan, Enrique Porto y Francisco Aló. Hiroshi Matsushita. Movimiento Obrero Argentino, 1930-1945..., Op. Cit., p. 153.

${ }^{19}$ XXIII Congreso Ordinario (XXX Congreso Nacional), Talleres Gráficos La Vanguardia, 1936, p. 51.

${ }^{20}$ Hugo del Campo. Sindicalismo y peronismo. Los comienzos de un vínculo perdurable (1983). Buenos Aires, Siglo Veintiuno Editores, 2005; Joel Horowitz. Los sindicatos, el Estado y el surgimiento de Perón, 1930-1946. Buenos Aires, Eduntref, 2004; Hernán Camarero. Comunismo y movimiento obrero..., Op. Cit. 


\section{El Partido Socialista y el movimiento sindical tras la conquista de la Confederación General del Trabajo (1935-1937)}

quedaba con una CGT Independencia compuesta por 113 organizaciones y agrupando a 263.000 afiliados y su secretario general era Luis Cerutti. ${ }^{21}$ Mientras que su rival con sede en la calle Catamarca quedaba con 116 sindicatos pero con la magra suma de 25.000 trabajadores, y se encontraba liderada por el también ferroviario Antonio Tramonti.

Tras la ruptura con el sector tradicional de la corriente sindicalista, la CGT parecía estar dispuesta a establecer una mayor ligazón con las corrientes políticas. Aunque se veían incapacitados de votar, los dirigentes comunistas se expresaron críticamente sobre la prescindencia y el proceder de la CGT hasta diciembre de 1935 y, de este modo, fortalecieron la línea de aquellos que propiciaban estrechar lazos con los partidos políticos. ${ }^{22}$ Pero ello pronto se demostró un diagnóstico incorrecto o apresurado. Raudamente quedaron representados dos bandos. El primero, compuesto por socialistas, algunos sindicalistas todavía existentes y los líderes ferroviarios, menos tendiente a involucrarse en cuestiones políticas y partidarias. Allí revistaban Domenech y Camilo Almarza, entre los dirigentes más importantes. El segundo, formado por los socialistas más ligados a la estructura del PS y los comunistas, más propensos a dirimir cuestiones a través de la política y los partidos, entre quienes estaban Pérez Leirós, Ángel Borlenghi y los comunistas Guido Fioravanti y Pedro Chiarante. Nuevamente, como en el período 1930-1935, la división parecía recortarse sobre la relación que debía establecerse con los partidos políticos. $^{23}$ Aunque en el Congreso Constituyente, los estatutos sancionados mencionaban la necesidad de intervenir en los problemas nacionales (artículo 5) y se había eliminado la incompatibilidad del cargo político y el gremial, resultaba evidente que el mantenimiento del artículo 4 acerca de la independencia de los partidos políticos o agrupaciones ideológicas comenzaba a arrojar luces sobre la línea de acción futura de la CGT. La permanencia del artículo 4, que estaba presente desde la fundación de la CGT, estuvo probablemente anclada en le necesidad de despejar las dudas sobre el rol de la CSIG, atender el todavía relevante sector sindicalista de la UF y armonizar la coexistencia entre socialistas y comunistas en la nueva central. ${ }^{24}$

\section{El nuevo viraje del PS}

\footnotetext{
21 Cerutti fue uno de los blancos de ataque principales por parte del sector depuesto pues se encontraba en funciones como secretario general durante el periodo 1930-1935 y fue quien permitió la entrada a la sede de la calle Independencia el día 12 de diciembre. Hugo del Campo. Sindicalismo y peronismo..., Op. Cit., p. 126. Cerutti quedó luego de diciembre al mando de una Junta Ejecutiva provisoria y ocupó ese cargo hasta junio de 1937 en donde Domenech asumió como secretario general.

22 "Impresiones de Guido Fioravanti sobre el Congreso Constituyente de la CGT", La Internacional, (Órgano del Partido Comunista de la Argentina), XIX, 3472, $2^{\circ}$ quincena de abril de 1936, p. 11.

${ }^{23}$ Hernán Camarero. “Del auge al declive: las corrientes de izquierda...”, Op. Cit.

${ }^{24}$ Hiroshi Matsushita. Movimiento Obrero Argentino, 1930-1945..., Op. Cit., p. 167.
} 


\section{Diego Ceruso}

Durante 1935, el PS comenzó a materializar una serie de modificaciones que implicaban un mayor control de la dirección sobre la esfera gremial del partido. El Congreso Extraordinario de mayo de 1935 fue el escenario en donde el CE del PS asestó otro duro golpe al 'ala izquierda'. Uno de los puntos a los cuales se oponía la 'izquierda' era una propuesta de reformas de estatutos que otorgaba a la dirección mayor poder e injerencia en las designaciones de la estructura partidaria. En este escenario, la CSIG volvió a manifestarse en acuerdo con el sector opositor y se opuso a la propuesta que la Comisión fuera designada por el CE del PS y no por los afiliados en asamblea, como había sido hasta entonces. ${ }^{25}$ Cabe preguntarse si el intento de centralización no se correspondía con el retroceso de las posiciones de la izquierda y el mayor control del CE que ya había obtenido un resultado favorable en el Congreso de 1934, reunido en Santa Fe. Como consecuencia de estos cambios en el estatuto, las comisiones de oficio fueron desmanteladas, las comisiones de coordinación impulsadas en la Circular $\mathrm{N}^{\circ} 4$ de la Comisión fueron incorporadas pero sin un peso objetivo dentro del PS y, como dijimos, los integrantes de la CSIG de allí en más serían elegidos por el CE y ya no por los afiliados en asamblea: "habían perdido, además, el derecho a elegir a los miembros de la Comisión Gremial, y con ello la posibilidad de incidir en la elaboración de la política del partido para la clase obrera. La nueva fórmula estatutaria establecía que 'El Comité Ejecutivo designará una Comisión de Información Gremial, que tendrá por función estimular y coordinar la acción gremial de los afiliados, quienes deberán constituirse en grupo y obrar en forma paralela y concordante con el partido. La Comisión estará integrada por quince afiliados que, siendo posible, ocupen cargos en las comisiones administrativa de la diversa organizaciones obreras, y un miembro del Comité Ejecutivo'. De esta manera, el partido preparaba mecanismos de control ante la creciente 'politización' de sus cuadros sindicales, con el fin de evitar que traspusieran los límites de 'su ámbito específico' y avanzaran sobre un terreno que considerado propio del organismo político. El recorte de su espacio dentro de la estructura partidaria era parte del ajuste de cuentas con la 'izquierda' partidaria, que no en vano acababa de ser derrotada".26 En consecuencia, tras esta variación estatutaria, resultaba imposible que la CSIG expresara algún tipo de disidencia respecto de la línea de la dirección partidaria.

Como mencionamos, el PS durante la primera mitad de la década de 1930 estuvo signado por las discusiones internas y por la aparición de un sector 'izquierdista' que tuvo un crecimiento por aquellos años y que entabló su enfrentamiento con la dirección en el XXII Congreso Ordinario reunido en mayo de 1934 en la ciudad de Santa Fe. ${ }^{27}$ Tras ese Congreso, el CE se encargó de restar posiciones a los opositores que se agrupaban principalmente entre la juventud, la

25 "La reforma de los estatutos y la Comisión Socialista de Información Gremial", Acción Gremial, editado por la Comisión Socialista de Información Gremial, XI, 40, abril de 1935, p. 1. Puede consultarse La Vanguardia de los días 27 y 28 de mayo de 1935 para dar cuenta de estas resoluciones finales del Congreso.

${ }^{26}$ María Cristina Tortti. “Estrategia del Partido Socialista...”, Op. Cit.

${ }^{27}$ Carlos Miguel Herrera. “Corrientes de izquierda en el socialismo argentino...”, Op. Cit., pp. 132 y ss. 


\section{El Partido Socialista y el movimiento sindical tras la conquista de la Confederación General del Trabajo (1935-1937)}

revista Izquierdas y la Federación Socialista Mendocina. La pugna se replicó en el Congreso Extraordinario de mayo de 1935 en donde el 'ala izquierda' fue nuevamente derrotada. La disputa interna se acrecentó con sucesos como la suspensión de la publicación de Izquierdas, en diciembre de 1935, y la expulsión del concejal capitalino Fortunato Zabala Vicondo, en octubre de $1936 .{ }^{28}$ Finalmente, los opositores a la conducción partidaria formaron la Comisión pro Unidad del Partido Socialista que en mayo de 1937 permitió la creación del Partido Socialista Obrero.

En paralelo a este retroceso y posterior expulsión del sector 'izquierdista', el PS comenzó a expresar una nueva modulación de su dinámica en el mundo gremial. Si la presencia de voces disonantes a la política oficial sobre la escisión entre el plano político y el gremial entre 1930 y 1935 fue una constante, ese escenario se modificó sustancialmente. La CSIG, en esos primeros años treinta fue una herramienta central para cuestionar la política oficial de la dirección, aunque años después, el cuadro gremial textil y socialista Lucio Bonilla expresara una idea disímil sobre su rol: "la Comisión de Información Gremial del Partido Socialista nunca orientó desde su seno las directivas que había que impartir a un sindicato, porque el afiliado socialista está educado para no aceptar eso. El afiliado socialista, a esta altura del sindicato tiene que cuidar mucho, mucho de su conducta. Nada más. Pero los lineamientos de su acción sindical deben estar trazados por los compañeros del sindicato. (...) Yo le digo porque yo he sido miembro de la Comisión de Información Nacional Gremial del Partido Socialista y he actuado por espacio de dos años con gente que ha sido destacada en el instante gremial de los distintos gremios del país. Y la orientación es ésa". ${ }^{29}$ En el mismo sentido, y quizá de modo peculiar pues se refería al sector de los gráficos en donde existían posturas encontradas sobre el vínculo entre partido y sindicato se pronunciaba René Stordeur: "y debo significar que había cierto orgullo de independencia en el militante sindical con respecto a su actividad como tal; los gráficos particularmente. Los gráficos no sometían sus decisiones, sus orientaciones y su acción dentro de la Federación Gráfica Bonaerense a lo que estrictamente, en algún momento, podía haberle interesado al Partido, sino que cuidaban de defender los intereses particulares del gremio por encima de todas las cosas". 30

A comienzos de 1936, el PS, a través de La Vanguardia, comenzó a definir su posición respecto de los incidentes ocurridos en la CGT y a reconstituir, probablemente, su estrategia en el plano sindical: "cualquiera que diga que el Partido Socialista se inmiscuye directamente como organismo político de los trabajadores en los sindicatos, miente a sabiendas. El Partido estuvo y está al servicio de los trabajadores, pero nunca ha hecho otra cosa que aconsejarlos, darles normas escritas, asumir su defensa en cuantas oportunidades fue posible. Jamás fue oficialmente a los sindicatos ni tomó injerencia alguna en sus cuestiones internas". ${ }^{31}$

\footnotetext{
${ }^{28}$ Nicolás Iñigo Carrera. “Alternativas revolucionarias en los '30...”, Op. Cit., p. 335.

${ }^{29}$ Entrevista a Lucio Bonilla, pp. 69 y 70, Archivo de Historia Oral, Instituto Di Tella.

${ }^{30}$ Entrevista a René Stordeur, p. 171, Archivo de Historia Oral, Instituto Di Tella.

31 "En torno a la CGT", La Vanguardia, XLII, 10377, 9/2/1936, p. 5.
} 


\section{Diego Ceruso}

A contramano, en el órgano oficial de la CGT Independencia, el sector más ligado a criticar fuertemente la prescindencia expresó rápidamente sus posiciones caracterizándola como la: "incapacidad de la organización para hacer respetar su autonomía, sin necesidad de fundarla en un compromiso, por sus cabales, por su esencia generatriz de la lucha de clases" y continuaba: "jamás una organización obrera con pulso vital puede renunciar a su derecho de intervención, en todas las formas de cometido social de carácter de izquierda". ${ }^{32}$ Pero las expresiones de la dirección del PS se redirigían en el sentido opuesto: "las presentes transcripciones dan una idea precisa acerca de la autonomía sindical, de la acción destructiva de las tendencias, de la coordinación en los planes, de la manera de vigorizar los cuadros gremiales y del perjuicio que el embanderamiento ocasiona". 33

Las publicaciones del PS no sólo insistían con los conceptos acerca de reposicionar la idea sobre la separación de la esfera política y la gremial sino que se pretendía relativizar, más bien otorgarle un nuevo sentido, a los sucesos ocurridos previamente: "la resolución del XXII Congreso Nacional celebrado en Santa Fe, hablaba de coordinar los actos para mayor vigor y eficacia de la acción (...)" ${ }^{34}$ Como dijimos, aquella resolución, más que proponer una 'coordinación de actos', contrariaba de modo explícito la política gremial de la dirección. Además, no faltaron en aquellos años la publicación de notas de Justo sobre el tema para dejar claro el sentido que debía tomar el proceder sindical socialista: "pero el Partido Socialista no debe inmiscuirse en la organización gremial. Colectivamente sólo puede y debe servirla desde afuera en cuanto las leyes, el gobierno y la administración pública atañen a la organización gremial". ${ }^{35}$ La ausencia de posturas contrarias a la dirección en las publicaciones socialistas en estos meses de 1936 y 1937 contrastaba notablemente con lo observado oportunamente para la primera mitad de la década. ${ }^{36}$

La llegada a la conducción de la CGT y el posicionamiento de Domenech como máxima figura en la central obrera, aunque asumiría la secretaría general a mediados de 1937, permiten suponer un acople entre la línea del PS y el pensar del líder ferroviario, que años después dejaba claro: “(...) pero, le voy a decir una cosa, que dentro del movimiento obrero jamás, jamás, se habló de política, jamás se habló de política, hasta el año 43, jamás se hablo de política. Yo he sido siempre apoyado por radicales, conservadores, socialistas, incluso comunistas, incluso comunistas; jamás se habló de política". Y en referencia a la Confederación Obrera Argentina, pero aplicable a la experiencia del PS de modo más global, planteaba: "no, no, mire, lo que había era esto, la COA naturalmente, en la COA había gente socialista, pero que el Partido Socialista, influyera en la COA, no. Pienso que nunca el Partido

\footnotetext{
32 CGT, ("Periódico de la Confederación General del Trabajo"), II, 99, 6/3/1936, p. 1.

${ }^{33}$ Nicolás Cuello, "Tarea gremial de los socialistas", Revista Socialista, VI, 72, mayo de 1936, p. 368.

${ }^{34}$ Nicolás Cuello, "Acción gremial de los socialistas", Revista Socialista, VII, 78, noviembre de 1936, p. 383.

35 “La organización gremial y el Partido Socialista", Revista Socialista, VIII, 86, julio de 1937, p. 3.

${ }^{36}$ Diego Ceruso. "El Partido Socialista y la cuestión gremial...", Op. Cit.
} 


\section{El Partido Socialista y el movimiento sindical tras la conquista de la Confederación General del Trabajo (1935-1937)}

Socialista, influyó, en ningún sindicato". ${ }^{37}$ En igual sentido recordaba Almarza, ladero de Domenech en la conducción de la CGT: "ahora, de ahí a embanderar al sindicalismo en una concepción política es una cosa distinta. Nosotros le atribuimos a los sindicalistas ser los promotores de la prescindencia sindical en el país, pero los que en realidad defendieron la prescindencia sindical en este país fuimos nosotros los socialistas a pesar de figurar como militantes de un partido político". ${ }^{38}$

Las diferencias entre los grupos en el interior de la central obrera se fueron evidenciando frente a numerosos acontecimientos, por ejemplo en los discursos en torno al acto unitario, tanto como inusual, del $1^{\circ}$ de mayo de 1936 que la CGT organizó y compartió con el PS, el PC, la Unión Cívica Radical, los demócratas progresistas, estudiantes y gremios autónomos, entre otros. Así se expresaba Domenech: "el movimiento gremial debe ser autónomo, neutral en las luchas electorales; vivir intensamente los problemas netamente sindicales (...)", (...) "se forma parte de la organización gremial para tener deberes y lograr derechos; nunca para defender tendencias políticas o creencias religiosas determinadas" (...) “y antes de finalizar estas palabras, quiero recordar a los trabajadores que el puesto de lucha de ellos se encuentra en el sindicato. No es explicable que en estos momentos difíciles para el país, y para los proletarios en particular, haya obreros alejados de la organización por influencias extrañas a la misma o por razones ideológicas, pues tal actitud importa servir al capitalismo y traicionar a sus hermanos de clase". 39 Domenech circunscribía la función sindical a las reivindicaciones económicas y ligadas al plano gremial aunque, tomando distancia de la postura más puramente sindicalista, guardaba cierta valoración en la sanción de leyes obreras en el parlamento y a ello reservaba el posible vínculo con los partidos políticos. La posible colaboración propuesta a través de la sanción de leyes en el parlamento se había convertido en una posibilidad incierta y alejada de la realidad producto de la ahora disminuida presencia socialista en el Congreso Nacional. ${ }^{40}$ En cambio, Pérez Leirós, buscando establecer puentes con las estructuras partidarias expresaba en el mismo acto: "se rompió así con casi medio siglo de apoliticismo infecundo, fomentado y estimulado por los enemigos de la emancipación proletaria, porque en tal forma esterilizaban su acción", aunque se expresó en favor del trabajo mancomunado con los partidos políticos no evitó recordar que debía guardarse lugar a la autonomía entre ambos ámbitos. ${ }^{41}$ Aunque pasados los años, Pérez Leirós expresara un balance opuesto sobre los valores del gremialismo: "los sindicatos de vida permanente y que han desarrollado una labor más fructífera en favor de la clase obrera han

\footnotetext{
${ }^{37}$ Entrevista a José Domenech, p. 26 y p. 72, Archivo de Historia Oral, Instituto Di Tella.

38 Entrevista a Camilo Almarza, p. 37. Archivo de Historia Oral, Instituto Di Tella.

39 "Discurso del presidente de la CGT, ciudadano José Domenech", La Vanguardia, XLIII, 10460, 3/5/1936, p. 2.

40 El PS, levantamiento de la abstención radical mediante, pasó de contar con 43 diputados en 1934, a 25 en 1936 y sólo 5 en 1939. Darío Cantón. Los partidos políticos argentinos entre 1912 y 1955, Documentos de Trabajo ${ }^{\circ} 31$, Buenos Aires, Instituto Torcuato Di Tella, 1967, pp. 26-27.

41 "Podemos mezclarnos sin temor a confundirnos, ya que cada uno conserva su libertad y autonomía. Expresó Pérez Leirós”, El Obrero Municipal, XVI, 302, 16/5/1936, p. 2.
} 


\section{Diego Ceruso}

evidenciado que el método de la autonomía sindical es el gran factor de convivencia que une a los hombres y hace eficientes a las entidades sindicales en la acción específica que les dan razón de ser". ${ }^{42} \mathrm{Al}$ año siguiente, en ocasión del acto del $1^{\circ}$ de mayo de 1937, la CGT se opuso a la organización conjunta con los partidos políticos dando un paso más en su línea de prescindencia. Así, gradual pero incesantemente, las posturas del PS y de la conducción de la CGT confluían en mantener autónomas la esfera política y la gremial.

\section{Palabras finales}

Tras la obtención de la conducción de la CGT, el PS pareció abandonar los debates de la primera mitad de la década del treinta. El Partido, principalmente su dirección, estructuró un nuevo 'retorno a Justo' y a su estrategia de independencia del plano político y el gremial. Esta división de esferas tuvo su ejemplificación más nítida en la virtual desaparición de la Comisión Socialista de Información Gremial como un organismo con posturas propias y críticas a la conducción partidaria, como había ocurrido en los años previos. Esta confluencia de la CSIG con la conducción, representada en su casi evaporación en estos meses, estuvo habilitada por la reforma de estatutos de 1935 que permitieron al CE elegir sus integrantes sin mediar la opinión de los afiliados. Dicha Comisión, durante estos meses de 1936 y 1937, no ejerció un rol de relevancia en el plano gremial y, al igual que las voces disidentes dentro del PS, no tuvo una presencia en las publicaciones partidarias que, más bien, se preocuparon por reponer la idea de la preeminencia de lo político, denunciar el embanderamiento sindical y destacar la centralidad de la prescindencia. Este panorama se complementó con las tenues expresiones críticas de Pérez Leirós durante el período, referente del grupo que propiciaba estrechar lazos entre el Partido y el movimiento obrero, y la pérdida de centralidad de la temática gremial en los Congresos partidarios de esos años, ambos elementos que contrastan con el momento inmediatamente anterior.

La consumada derrota de la 'izquierda' del Partido y el desplazamiento de los sindicalistas de la CGT hacían ya innecesario un discurso contrario a la prescindencia. Además, la independencia de esferas servía ahora a los intereses de denunciar el proceder de los comunistas y su política de 'tutelaje' en los cada vez más pujantes sindicatos industriales, tras la adopción de la estrategia del 'frente popular' y su incorporación a la CGT. Así, la prescindencia socialista funcionaba, también, como un dique de contención frente al avance gremial del PC y la presión que éste ejercía.

Tras la separación de la conducción sindicalista de la CGT, el PS adoptó nuevamente la prescindencia, entendida como separación de lo político y lo sindical, como planteo frente al mundo gremial. Aún más, promovió esa prescindencia y allí pudo confluir con el sector liderado por Domenech. Aunque ello no implicó las

${ }^{42}$ Francisco Pérez Leirós. Grandezas y miserias de la lucha obrera. Buenos Aires, Libera, 1974, p. 59. 


\section{El Partido Socialista y el movimiento sindical tras la conquista de la Confederación General del Trabajo (1935-1937)}

desavenencias en otros aspectos entre el PS y la CGT. Esta incapacidad y desinterés del PS por estructurar una estrategia firme para influir en el movimiento obrero habilitó a la CGT, y a su conducción, a construir una senda autónoma y anclada en reclamos económicos y meramente sindicales. Hacia adelante, esta tendencial conducta sería cuestionada dentro de la central obrera, por comunistas y socialistas que propiciaban acercar su dinámica a los partidos políticos.

En los años siguientes, dos elementos parecieron confirmarse. Uno, la reafirmación de la independencia del ámbito político del gremial por parte del PS y, segundo, la materialización del PC como un actor de fuste en el movimiento obrero, fundamentalmente industrial. Ambos actores, PS y PC, se manifestarían conformes con dicho escenario quizá replicando un nuevo "modelo de convivencia" en donde el interés prioritario electoralista y parlamentarista del PS se combinara con un énfasis del PC en el mundo sindical. ${ }^{43} \mathrm{Si}$ a comienzos del siglo XX el PS había podido estructurar esta suerte de "división del trabajo" producto del apoliticismo sindicalista, ahora se debía en mayor medida a la imposibilidad del PC de participar en elecciones como consecuencia de su status ilegal, primero, y su escasa incidencia en el plano electoral, luego.

Resta saber, trabajo que emprenderemos hacia adelante, el modo en el que este escenario evolucionó. En los años finales de la década infame, el proceder gremial del PS todavía presenta aristas a profundizar. El contexto de mayor enfrentamiento entre los líderes de la CGT y los dirigentes comunistas y socialistas más ligados al Partido convirtió a la central obrera en una caja de resonancia y a la experiencia sindical de estos años en la arena en donde se saldaron múltiples debates en los cuales el PS intervino y delineó su estrategia, o la ausencia de ella, de cara al movimiento obrero.

\section{Bibliografía}

Aricó, José. La hipótesis de Justo. Escritos sobre el socialismo en América Latina. Buenos Aires, Sudamericana, 1999.

Camarero, Hernán, "Socialismo y movimiento sindical: una articulación débil. La COA y sus relaciones con el PS durante la década de 1920". En Hernán Camarero y Carlos Miguel Herrera, El Partido Socialista en Argentina: sociedad, política e ideas a través de un siglo, Buenos Aires, Prometeo, 2005, pp. 185-217.

\footnotetext{
${ }^{43}$ Así se describía el mencionado "modelo de convivencia": "lo que nosotros sostenemos es que la verdadera cuestión que subyacía a esta polémica, fue la relación que se debía o se podía establecer entre sindicato y partido. Los socialistas reformistas venían a postular la neutralidad y la autonomía entre uno y otro; esto era coherente con su concepción electoralista según la cual las mejoras que obtendría la clase trabajadora se conseguirían mediante la legislación y la acción parlamentaria. Los sindicalistas revolucionarios empalmaban con esta posición; y, en definitiva, para ellos estaba reservado el control de los gremios. Era una suerte de 'división del trabajo'; el reformismo de unos, se articulaba con el apoliticismo de otros". Hernán Camarero y Alejandro Schneider. La polémica Penelón-Marotta (marxismo y sindicalismo soreliano, 1912-1918). Buenos Aires, CEAL, 1991, pp. 6061.
} 


\section{Diego Ceruso}

Camarero, Hernán, A la conquista de la clase obrera. Los comunistas y el mundo del trabajo en la Argentina, 1920-1935. Buenos Aires, Siglo XXI, 2007.

Camarero, Hernán, Comunismo y movimiento obrero en la Argentina, 1914-1943. Tesis de doctorado, Buenos Aires, Universidad de Buenos Aires, 2008.

Camarero, Hernán, "Del auge al declive: las corrientes de izquierda y los trabajadores antes del peronismo. Elementos para una interpretación teórica e historiográfica global”. Iberoamérica Global, núm. 2, Jerusalém, 2011, pp. 49-79.

Camarero, Hernán, "La CGT en disputa. Prescindencia apolítica de la dirección sindicalista y frentepopulismo comunista, 1935-1939”. Cuadernos del Ciesal, vol. XII, núm. 14, Rosario, 2015, pp. 35-58.

Camarero, Hernán, y Alejandro Schneider. La polémica Penelón-Marotta (marxismo y sindicalismo soreliano, 1912-1918). Buenos Aires, CEAL, 1991.

Cantón, Darío. Los partidos políticos argentinos entre 1912 y 1955, Documentos de Trabajo $n^{\circ} 31$, Buenos Aires, Instituto Torcuato Di Tella, 1967.

Casaretto, Martín. Historia del movimiento obrero argentino, Buenos Aires, Lorenzo, 1946.

Ceruso, Diego, La izquierda en la fábrica. La militancia obrera industrial en el lugar de trabajo, 1916-1943. Colección Archivos, Buenos Aires, Imago Mundi, 2015.

Ceruso, Diego, "El Partido Socialista y la cuestión gremial. Debates internos durante la primera mitad de la década infame". Archivos de historia del movimiento obrero y la izquierda, V, 10, Buenos Aires, 2017, pp. 119-139.

Cheresky, Isidoro. "Sindicatos y fuerzas políticas en la Argentina preperonista (1930-1943)". En P. González Casanova (coordinador). Historia del movimiento obrero en América latina. vol. 4. México, Siglo XXI, 1984.

del Campo, Hugo. Sindicalismo y peronismo. Los comienzos de un vínculo perdurable (1983). Buenos Aires, Siglo Veintiuno Editores, 2005.

Dickmann, Enrique. Socialismo y gremialismo. Buenos Aires, Pequeño Libro Socialista, 1946.

Dickmann, Adolfo. Los Congresos Socialistas. 40 años de Acción Democrática. Buenos Aires, La Vanguardia, 1936.

Dorfman, Adolfo. Historia de la industria argentina, Buenos Aires, Hyspamérica, 1986.

García, Leandro. "En torno al concepto de "prescindencia": la corriente sindicalista al frente de la CGT (1930-1935)". Archivos de historia del movimiento obrero y la izquierda, V, 10, Buenos Aires, 2017, pp. 95-115.

Godio, Julio. El movimiento obrero argentino (1930-1943). Socialismo, comunismo y nacionalismo obrero, Buenos Aires, Legasa, 1989.

Herrera, Carlos Miguel. "Corrientes de izquierda en el socialismo argentino, 19321955”. Nuevo Topo. Revista de historia y pensamiento crítico, 2, Buenos Aires, 2006, pp. 127-153.

Horowitz, Joel. Los sindicatos, el Estado y el surgimiento de Perón, 1930-1946. Buenos Aires, Eduntref, 2004. 


\section{El Partido Socialista y el movimiento sindical tras la conquista de la Confederación General del Trabajo (1935-1937)}

Iñigo Carrera, Nicolás, La estrategia de la clase obrera, 1936 (2000). Buenos Aires, Ediciones Madres de Plaza de Mayo, 2004.

Iñigo Carrera, Nicolás, La otra estrategia. La voluntad revolucionaria (1930-1935). Buenos Aires, PIMSA-Imago Mundi, 2016.

Iñigo Carrera, Nicolás, "Alternativas revolucionarias en los '30: la Alianza Obrera Spartacus y el Partido Socialista Obrero". En Hugo Biagini y Arturo Roig (directores). El pensamiento alternativo en la Argentina del siglo XX. Tomo II. Obrerismo, vanguardia, justicia social (1930-1960), Buenos Aires, Editorial Biblos, 2006.

Justo, Juan B. "La organización obrera y el Partido Socialista". En Obras de Juan B. Justo, tomo 6, La realización del socialismo. Buenos Aires, La Vanguardia, 1947.

López, Alfredo, Valor del sindicato obrero. Buenos Aires, Pequeño Libro Socialista, 1935.

López, Alfredo, Historia del movimiento social y de la clase obrera argentina (1971). Buenos Aires, Peña Lillo, 1974.

Marotta, Sebastián. El movimiento sindical argentino. Su génesis y desarrollo. Tomo III. Período 1920-1935. Buenos Aires, Lacio, 1970.

Martínez, Ilana. Por la vuelta a Marx. El ala izquierda del Partido Socialista Argentino, 1929-1935. Tesis de maestría, Buenos Aires, Universidad Nacional de General San Martín, 2012.

Martínez Mazzola, Ricardo. "La neutralidad como problema y como solución. La política gremial del Partido Socialista después de la ruptura sindicalista". Identidades, I, 1, Buenos Aires, 2011, pp. 1-20.

Matsushita, Hiroshi. Movimiento Obrero Argentino, 1930-1945: Sus proyecciones en los orígenes del peronismo. Buenos Aires, Hyspamérica, 1986.

Oddone, Jacinto, Historia del socialismo argentino (1934), 2 tomos. Buenos Aires, CEAL, 1983.

Oddone, Jacinto, Gremialismo proletario argentino. Buenos Aires, La Vanguardia, 1949.

Pérez Leirós, Francisco. Grandezas y miserias de la lucha obrera. Buenos Aires, Libera, 1974.

Tortti, María Cristina. "Estrategia del Partido Socialista. Reformismo político y reformismo sindical". En Conflictos y Procesos de la Historia Argentina Contemporánea, № 34, Buenos Aires, CEAL, 1989.

Recibido: 23/05/2017

Evaluado: 01/06/2017

Versión Final: 19/07/2017 